\title{
Avaliação de objeto virtual de aprendizagem sobre pré- natal para adolescentes grávidas na atenção básica
}

Evaluation of a prenatal virtual learning object for pregnant adolescents in primary care Evaluación de objeto virtual de aprendizaje sobre prenatal para adolescentes embarazadas en la atención básica

\author{
Roberta Fortes Santiago ${ }^{1}$ iB https://orcid.org/0000-0002-3642-9648 \\ Elaine Maria Leite Rangel Andrade ${ }^{1}$ iD https://orcid.org/0000-0002-1772-7439 \\ Isabel Amélia Costa Mendes² id https://orcid.org/0000-0002-0704-4319 \\ Maria Corina Amaral Viana ${ }^{3}$ io https://orcid.org/0000-0002-6890-9400 \\ Inez Sampaio Nery' io https://orcid.org/0000-0001-7820-0991
}

\section{Como citar:}

Santiago RF, Andrade EM, Mendes IA, Viana MC, Nery IS. Avaliação de objeto virtual de aprendizagem sobre pré-natal para adolescentes grávidas na atenção básica. Acta Paul Enferm. 2020;33:eAPE20190063.

DOI http://dx.doi.org/10.37689/ acta-ape/2020A00063

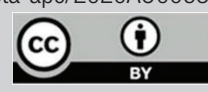

Descritores

Gravidez na adolescência; Educacãa em saúde; Tecnologia educacional; Educação à distancia; Materiais de ensino

Keywords

Pregnancy in adolescence; Health education; Education technology; Education, distance; Teaching materials

Descriptores

Embarazo en adolescência; Educación en salud; Tecnología educacional; Educación a distancia; Materiales de enseñanz

Submetido 19 de Março de 2019

Aceito

8 de Outubro de 2019

Autor correspondente

Roberta Fortes Santiago

E-mail: betafortes@yahoo.com.br

\section{Resumo}

Objetivo: Descrever o processo de construção e avaliação de um Objeto Virtual de Aprendizagem sobre prénatal para adolescentes grávidas no contexto da atenção básica.

Métodos: Trata-se de um estudo metodológico, tecnológico de abordagem quantitativa realizado em cinco fases: análise, design, desenvolvimento, implementação e avaliação da qualidade do Objeto Virtual por cinco juízes em Enfermagem em Saúde da Mulher usando o Learning Object Review Instrument e ergonomia por cinco juízes em Informática de acordo com variáveis relacionadas a funcionalidade, usabilidade e eficiência.

Resultados: 0 Objeto Virtual foi intitulado GESTAQ. Na avaliação dos juízes em Enfermagem em Saúde da Mulher, com exceção da usabilidade interativa, os outros itens relativos à qualidade do Objeto Virtual de Aprendizagem obtiveram percentual igual ou superior a 80\%. Enquanto, na avaliação dos juízes em Informática, todas as variáveis relacionadas a funcionalidade, usabilidade e eficiência obtiveram percentual igual ou superior a $80 \%$. Destacou-se como sugestão apontada por estes juízes a melhoria do layout, que foi atendida.

Conclusão: 0 Objeto Virtual de Aprendizagem foi avaliado de forma satisfatória por juízes em Enfermagem em Saúde da Mulher e Informática, quanto a qualidade e ergonomia. Desta forma, acredita-se que o GESTAQ possa ser usado como recurso digital complementar ao processo educativo de adolescentes grávidas no contexto da atenção básica para fornecer orientações sobre pré-natal.

\section{Abstract}

Objective: Describe the construction and evaluation process for a prenatal virtual learning object for pregnant adolescents within the primary care context.

Methods: This is methodological, technological study with a quantitative approach carried out in five stages: analysis, design, development, implementation and assessment of the quality of a virtual object by five judges from the field of nursing in women's health, using the Learning Object Review Instrument, and in terms of ergonomics by five judges from the field of informatics, according to variables related to functionality, usability and efficiency.

Results: The virtual object was entitled GESTAQ. In the evaluation of the judges from nursing in women's health, with the exception of interactive usability, the other items related to the quality of the virtual learning object obtained scores greater than or equal to $80 \%$. In turn, in the evaluation of the judges in informatics, all the variables related to functionality, usability and efficiency obtained scores greater than or equal to $80 \%$. There was a suggestion by these judges to improve the layout, which was implemented.

Conclusion: The virtual learning object was evaluated satisfactorily by judges in the fields of nursing in women's health and informatics, in regard to quality and ergonomics. Therefore, it is considered that 
GESTAQ may be used as a supplementary digital resource for the educational process of pregnant adolescents within the primary care context to provide prenatal guidance.

\section{Resumen}

Objetivo: Describir el proceso de construcción y evaluación de un Objeto Virtual de Aprendizaje sobre prenatal para adolescentes embarazadas en el contexto de la atención básica.

Métodos: Se trata de un estudio metodológico, tecnológico de enfoque cuantitativo realizado en cinco fases: análisis, diseño, desarrollo, implementación y evaluación de calidad del Objeto Virtual por cinco jueces de Enfermería en Salud de la Mujer, utilizando el Learning Object Review Instrument, y ergonomía por cinco jueces de Informática de acuerdo con variables relacionadas con funcionalidad, usabilidad y eficiencia.

Resultados: El Objeto Virtual fue titulado GESTAQ. En la evaluación de los jueces de Enfermería en Salud de la Mujer, a excepción de la usabilidad interactiva, los otros ítems relativos a la calidad del Objeto Virtual de Aprendizaje obtuvieron un porcentaje igual o superior a 80\%. Mientras que en la evaluación de los jueces de Informática, todas las variables relacionadas con funcionalidad, usabilidad y eficiencia obtuvieron un porcentaje igual o superior a 80\%. Se destacó como sugerencia señalada por estos jueces la mejora del diseño, la cual fue atendida.

Conclusión: El Objeto Virtual de Aprendizaje fue evaluado de forma satisfactoria por jueces de Enfermería en Salud de la Mujer e Informática, respecto a la calidad y ergonomía. De esta forma, se cree que el GESTAQ puede ser usado como recurso digital complementario en el proceso educativo de adolescentes embarazadas en el contexto de la atención básica para ofrecer instrucciones sobre prenatal.

\section{Introdução}

É crescente o número de intervençóes realizadas com o uso das Tecnologias de Informaçáo e Comunicação (TICs) para divulgação de informações sobre promoção da saúde, prevenção e monitoramento de doenças. ${ }^{(1-3)}$

Com o avanço do uso das TICs, os Objetos Virtuais de Aprendizagem (OVAs), que são definidos como qualquer recurso digital que possa ser utilizado para apoiar o processo de ensino-aprendizagem proporcionam reusabilidade, interatividade, interoperalidade, durabilidade e acessibilidade. ${ }^{(4-5)}$

Este cenário favoreceu a produção dos OVAs na área da saúde para apoiar o processo de ensino -aprendizagem sobre diversos temas e públicos-al$\mathrm{vo}^{(6-10)} \mathrm{e}$ torná-lo mais colaborativo, atrativo e autônomo para o aluno. ${ }^{(11)}$

No caso do pré-natal, a construção dos OVAs ainda precisa ser explorada como recurso tecnológico de apoio às atividades educativas sobre esse tema com adolescentes grávidas no contexto da atenção básica. Atividades educativas realizadas no pré-natal de adolescentes grávidas apenas com estratégias presenciais apresentam pouca adesão, devido à falta de interesse nos assuntos abordados e vergonha de partilhar dúvidas e dificuldades com as outras participantes. ${ }^{(12)}$ Por outro lado, o uso de estratégias (manuais, folhetos, slides e CDs) que podem ser revisadas pelas adolescentes grávidas sem a necessidade de estarem presentes nos serviços de saúde é mais efetivo nos níveis de adaptação pré e pós-parto. ${ }^{(13)}$
O uso dos OVAs pode ser recurso valioso de apoio às atividades educativas no pré-natal de adolescentes grávidas no contexto da atenção básica, considerando que este público obtém informaçôes sobre saúde usando TICs. Estudo realizado na França citou que quase todos os participantes da pesquisa entre 15 e 30 anos eram usuários de TICs e metade usava a Internet para obter informaçóes sobre saúde, aumentando significativamente com a idade: $39,3 \%, 50,4 \%$ e $55,4 \%$ para as faixas etárias de 15 a 19 anos, 20 a 25 e 26 a 30 anos, respectivamente $(\mathrm{P}=.002) .{ }^{(14)}$ Outro estudo realizado na Espanha evidenciou que dos 405 adolescentes que participaram da pesquisa $53,8 \%$ buscavam informaçóes sobre saúde na Internet, $21,5 \%$ tinham interesse nos temas gravidez e anticoncepção e 70,7 $\%$ afirmaram mudança de comportamento devido a informaçôes sobre saúde encontradas na Internet. ${ }^{(15)}$ Entretanto, informaçóes desqualificadas sobre saúde podem representar riscos. Portanto, a avaliação da qualidade dos aspectos pedagógicos e técnicos dos OVAs é necessária. ${ }^{(16)}$

Acredita-se que o OVA sobre pré-natal para adolescentes grávidas no contexto da atenção básica possa representar recurso digital alternativo para o desenvolvimento de atividades educativas com este público-alvo visando obter melhores resultados em relação a promoção da saúde materno-infantil e redução riscos biopsicossociais.

Este estudo teve como questão: Qual a avaliação dos juízes em Enfermagem em Saúde da Mulher e Informática em relação ao Objeto Virtual de 
Aprendizagem sobre pré-natal para adolescentes grávidas no contexto da atenção básica? Para respondê -la, o estudo foi realizado com objetivo de descrever o processo de construção e avaliação de um Objeto Virtual de Aprendizagem sobre pré-natal para adolescentes grávidas no contexto da atenção básica.

\section{Métodos}

Trata-se de um estudo metodológico, tecnológico de abordagem quantitativa, realizado no período de julho de 2017 a março de 2018, após aprovação do Comitê de Ética em Pesquisa, sob o número de protocolo 1.837.209 e Certificado de Apresentação para Apreciação Ética - CAAE: 59795616.0.0000.5214. Estudos metodológicos se referem às investigaçóes dos métodos de obtenção, organização e análise dos dados, para que ocorra a elaboração, validação e avaliação de instrumentos e técnicas de pesquisa, com objetivo de construir um instrumento que seja confiável, preciso e utilizável. ${ }^{(17)}$

Para construção e validação do OVA sobre prénatal para adolescentes grávidas no contexto da atenção básica utilizou-se as fases do modelo do Design Instrucional Contextualizado (DIC): análise, design, desenvolvimento, implementação e avaliação. $\mathrm{O}$ que diferencia o DIC do modelo convencional de construção de programas educativos online é que as fases não são progressivas, mas interativas. ${ }^{(18)}$

$\mathrm{Na}$ fase de análise, para determinar o conteúdo e os objetivos educacionais do OVA, a pesquisadora abordou 149 adolescentes grávidas cadastradas em Unidades Básicas de Saúde (UBS) de Teresina, com o intuito de identificar as principais necessidades de aprendizagem que este público-alvo tinha em relação ao pré-natal. Destas, 88 foram selecionadas por conveniência, a partir dos seguintes critérios de inclusão: realizar acompanhamento de pré-natal em uma das equipes de Estratégia Saúde da Família (ESF) vinculadas às UBS de Teresina e ter acesso ao computador ou telefone celular com internet. E, como critério de exclusão: não comparecer na UBS no dia da consulta de pré-natal.

Para caracterização sociodemográfica, uso das TICs e identificação das necessidades de aprendi- zagem das adolescentes grávidas foram utilizados dois instrumentos. $\mathrm{O}$ primeiro de caracterização e uso de TICs adaptado da literatura ${ }^{(19)}$ e o segundo sobre pré-natal elaborado a partir de protocolo do Ministério da Saúde sobre o tema. ${ }^{(20)}$ A coleta de dados foi realizada após autorização formal das adolescentes grávidas, mediante assinatura do Termo de Consentimento Livre e Esclarecido (TCLE) ou do Termo de Assentimento Livre e Esclarecido (TALE), no caso de adolescentes grávidas com idade inferior a 18 anos, que foi precedido da assinatura do TCLE pelos pais ou responsável.

Os objetivos educacionais foram formulados com apoio da Taxonomia de Bloom, que busca garantir a aquisição de competências, conhecimentos e habilidades no processo educativo, por meio do desenvolvimento dos domínios cognitivo, afetivo e psicomotor. ${ }^{(21)} \mathrm{O}$ conteúdo considerou as necessidades de aprendizagem do público-alvo (adolescentes grávidas) sobre a temática e o Manual de Atenção ao Pré-Natal do Ministério da Saúde. ${ }^{(20)}$

No design, foi constituída uma equipe de trabalho para criação do OVA (pesquisadora e web designer) e o mapa de navegação, sequência das telas de cada unidade de ensino, ferramentas de interação, mídias e cronograma do OVA definidos.

No desenvolvimento, a pesquisadora e o web designer produziram os roteiros das mídias impressas (textos produzidos pelo conteudista), imagens (representação visual da adolescente grávida e objetos produzidos pelo web designer), áudios, vídeos e fóruns de discussão das unidades de ensino por meio de roteiro do tipo storyboard. O roteiro conta a história de uma adolescente que ficou grávida, vivenciou a angústia de dar esta notícia para os pais e as descobertas e transformaçóes ocasionadas pela gestação. Mas, a adolescente foi encaminhada para as consultas de pré-natal na UBS e recebeu orientaçôes que esclareceram suas dúvidas. A história da adolescente foi transformada em mídias impressas produzidas no editor de texto Microsoft Office Power Point (Microsoft, Redmond, Washington DC, United States). Imagens no Photoshop CS2 9 software (Adobe ${ }^{\circledast}$ Inc., San Jose, CA, USA). Áudios gravados através do Final Cut Pro versão 10.4.6 (Apple ${ }^{\odot}$ Computer, Inc., CUPERTINO, CA, USA). E, fóruns 
de discussão ferramenta de interação assíncrona criada para estimular a interação entre a pesquisadora e as adolescentes grávidas e proporcionar apresentação, discussão, exposição e esclarecimento de dúvidas que elas pudessem ter sobre o pré-natal. As mídias impressas, imagens e áudios compuseram os vídeos das unidades de ensino que foram divididas em cinco semanas e compartilhados no You Tube.

$\mathrm{Na}$ implementação, o OVA foi hospedado no Ambiente Virtual de Aprendizagem (AVA) WordPress. Este ambiente possui dois tipos de usuários, administradores e participantes. $\mathrm{O}$ web designer e a pesquisadora foram administradores do AVA. Enquanto, os juízes em Saúde da Mulher e Informática foram os primeiros participantes, que avaliaram o OVA, antes da sua implementação com adolescentes grávidas. $\mathrm{O}$ web designer foi responsável pela arquitetura e lançamento das unidades de ensino semanalmente e a pesquisadora pelo cadastramento dos usuários e gerenciamento do AVA. O OVA podia ser acessado por usuários cadastrados no endereço eletrônico: http://gestaq.saude.ws/courses/gestaq. Nesta fase, quatro tutores estimularam o acesso e interatividade e ofereceram suporte técnico para os usuários do OVA. O WhatsApp também foi usado para facilitar e aumentar a interação entre a pesquisadora e as adolescentes grávidas.

O OVA foi avaliado para garantir sua confiabilidade e efetividade. A avaliação da qualidade foi realizada por juízes em Enfermagem em Saúde da Mulher e a ergonômica, por juízes em Informática. Para isto, contou-se com uma amostra de conveniência composta por dez juízes, sendo cinco em Enfermagem em Saúde da Mulher e cinco em Informática, selecionados por meio da técnica bola de neve, ${ }^{(17)}$ a partir dos critérios de inclusão definidos por dois instrumentos adaptados, ${ }^{(22)}$ um para cada área profissional, sendo estabelecido no mínimo cinco pontos para juízes em Enfermagem em Saúde da Mulher e três pontos para juízes em Informática nestes critérios, para participarem do estudo. A literatura recomenda quantitativo entre seis e 20 juízes, sendo necessários no mínimo três juízes em Enfermagem em Saúde da Mulher e três em Informática para validar a tecnologia informacional e educacional sobre pré-natal para adolescentes grávidas no contexto da atenção básica. ${ }^{(23)}$
Para os juízes em Enfermagem em Saúde da Mulher, responsáveis pela avaliação da qualidade do Objeto Virtual de Aprendizagem sobre pré-natal para adolescentes grávidas no contexto da atenção básica foi aplicado o Learning Object Review Instrument (LORI 2.0), que objetiva padronizar a avaliação de qualidade de softwares educacionais e é formado por nove critérios: qualidade do conteúdo; alinhamento aos objetivos de aprendizagem; feedback e adaptação; motivação; apresentação do projeto; interação e usabilidade; acessibilidade; reusabilidade; conformidade com normas. ${ }^{(24)} \mathrm{Cada}$ critério é avaliado por escala do tipo Likert, com pontuaçóes que variam de 1 a 5 (1=baixa qualidade e $5=$ alta qualidade).

Para avaliação ergonômica, foi aplicado para os juízes em Informática um instrumento com três variáveis: funcionalidade (capacidade do AVA de atender às funçóes para satisfazer as necessidades educativas de gestantes adolescentes); usabilidade (capacidade do AVA de ser compreendido, aprendido, operado e atraente às gestantes adolescentes); e eficiência (capacidade do AVA de apresentar desempenho apropriado, relativo à quantidade de recursos usados sob condiçóes especificadas). Cada variável é avaliada pela escala tipo Likert, com pontuaçóes que variam de 1 a 4 (1=inadequado, 2 =pouco adequado, 3 =adequado, 4=muito adequado), e no final de cada instrumento, há um espaço para inserção de críticas, sugestôes e/ou recomendaçôes. ${ }^{(25)}$

Para a coleta de dados com os juízes foi enviada carta convite por mensagem eletrônica (e-mail), para participarem do processo de validação, sendo explicados os objetivos, bem como enviado o TCLE e o instrumento para validação. Foram considerados como recusa à participação no estudo, os casos em que náo houve resposta ao convite por mensagem eletrônica (e-mail), após três tentativas, em um período de 15 dias. Foram contatados por mensagem eletrônica (e-mail) onze juízes em Enfermagem e nove em Informática, destes, apenas um de cada área deu retorno, momento em que se iniciou a técnica de bola de neve. Nos casos em que houve concordância em participar da pesquisa, os juízes assinaram o TCLE e o devolveram para pesquisadora por e-mail. Na sequência, os juízes foram re- 
gistrados pela pesquisadora e receberam o nome de usuário e uma senha para acessar o OVA sobre pré-natal para adolescentes grávidas no contexto da atenção básica. Após navegação e análise, responderam ao instrumento de validaçáo e o enviaram por mensagem eletrônica (e-mail).

Os dados obtidos foram codificados para elaboração de um dicionário de dados e, em seguida, realizada a transcriçáo, pelo processo de dupla digitação, utilizando planilhas do programa Microsoft Excel 2010. Uma vez corrigidos os erros, os dados foram exportados e analisados no programa Statistical Package for the Social Sciences versão 20 for Windows (IBM SPSS ${ }^{\circ}$ Nova York, United States). Nas características sociodemográficas, obstétricas, uso das TICs e necessidades de aprendizagem de gestantes adolescentes foi realizada análise estatística descritiva, na qual as variáveis qualitativas foram descritas por frequências absolutas e relativas, e as variáveis quantitativas por média, desvio padrão, mínimo e máximo.

$\mathrm{Na}$ caracterização dos juízes, foram utilizadas frequências (absolutas e relativas) para variáveis qualitativas e média, desvio padrão, mínimo e máximo para variáveis quantitativas. $\mathrm{Na}$ avaliação das respostas dos juízes para validação da tecnologia informacional e educacional sobre pré-natal, foi utilizada a escala adaptada por Sperandio, que considera como recomendada a conformidade de cada requisito (variável), valores superiores a $70 \%$ das respostas positivas dos juízes. ${ }^{(26)}$ As variáveis relacionadas a esta avaliação foram submetidas à análise estatística descritiva (frequências absoluta e relativa).

\section{Resultados}

\section{Caracterização das adolescentes grávidas, identificação das necessidades de aprendizagem, definição dos objetivos educacionais e conteúdo}

A idade média do público-alvo (88 adolescentes grávidas) foi de 16,6 anos $(\mathrm{DP} \pm 1,6)$. A maioria estava em união estável $(41-46,6 \%)$ e parda (67 - 76,1\%). Predominou o ensino fundamental (45

- 55,1\%) e a maior parte das adolescentes grávidas estavam estudando $(48-54,5 \%)$. Daquelas que in- terromperam os estudos (13 - 14,8\%) a principal causa foi a gestação. A maioria tinha renda familiar mensal inferior a dois salários mínimos, 45,5\% (40) viviam com renda inferior a 1 salário mínimo, e 48,9\% (43) apresentavam renda entre 1 e menos de dois salários mínimos, predominando as que não trabalhavam $(85-96,6 \%)$ e contavam com apoio da família (84-95,5\%).

A maioria possuía algum dispositivo tecnológico $(73-83 \%)$ e o telefone celular foi o principal dispositivo $(70-79,5 \%)$. Uma pequena parte usava o computador $(12-13,6 \%)$ e o tablet $(02-2,3 \%)$. Quase todas usavam diariamente algum dispositivo tecnológico $(76-86,4 \%)$, principalmente em casa $(85-96,6 \%)$. Em relação à internet, a maior parte acessava diariamente $(66-75 \%)$ e predominantemente em casa $(81-92 \%)$. O meio de informação mais utilizado para esclarecer dúvidas sobre a gravidez foi a internet $(60-68,2 \%)$, seguido da família, vizinhos e/ou amigos $(51-58 \%)$, posto de saúde $(31-35,2 \%)$ e profissionais de saúde $(29-33 \%)$.

A maioria nunca participou de atividade educativa no pré-natal $(68-77,3 \%)$. Foi identificado um total de 564 necessidades de aprendizagem (100\%). As necessidades de aprendizagem sobre gravidez, parto, pós-parto mais apontadas pelas adolescentes grávidas como responsáveis por ocasionar dúvidas e desejo de receber orientaçóes foram: cuidados com o recém-nascido $(60-10,6 \%)$; sinais de alerta para o parto $(50-8,9 \%)$; preparo para o parto (48 $8,5 \%)$; medos e fantasias referentes à gestação e ao parto $(46-8,2 \%)$; cuidados de higiene da gestante (44-7,8\%); tipos de parto (43 - 7,6\%); importância do pré-natal $(40-7,1 \%)$; e desenvolvimento da gestação $(40-7,1 \%)$.

Os objetivos educacionais e o conteúdo foram organizados de acordo com o exposto:

Objetivo geral: melhorar a qualidade de vida das adolescentes grávidas.

\section{Unidades de ensino/Objetivos específicos:}

Semana 1: ambientação das adolescentes grávidas ao Objeto Virtual de Aprendizagem sobre pré-natal no contexto da atençáo básica

- Realizar ambientação das adolescentes grávidas ao Objeto Virtual de Aprendizagem sobre pré-natal. 
Semana 2: importância do pré-natal e desenvolvimento da gestaçáo

- Conhecer a importância do pré-natal e as modificaçóes ocasionadas pela gestação;

- Refletir sobre as modificaçóes biopsicossociais da gestação na adolescência;

- Avaliar criticamente a necessidade de ser submetida à consulta por profissionais de saúde durante o pré-natal;

- Interagir com os profissionais de saúde, parceiro, familiares e outras gestantes.

Semana 3: dúvidas, medos e fantasias referentes à gravidez e cuidados de higiene durante a gravidez

- Esclarecer dúvidas, medos e fantasias comuns que podem acometer a mulher durante a gestação;

- Adotar hábitos de higiene adequados durante o período gestacional;

- Interagir com os profissionais de saúde, parceiro, familiares e outras gestantes.

Semana 4: preparo para o parto, sinais de alerta para o parto e tipos de parto

- Compreender o preparo para o parto;

- Conhecer diferença, vantagens e desvantagens dos partos normal e cesariano;

- Identificar o início do trabalho de parto;

- Adotar medidas para garantir parto e nascimento saudáveis;

- Interagir com os profissionais de saúde, parceiro, familiares e outras gestantes.

Semana 5: cuidados com o recém-nascido

- Compreender os cuidados a adotar com o recém-nascido;

- Identificar as necessidades do recém-nascido;

- Executar cuidados para garantir a satisfação das necessidades do recém-nascido;

- Interagir com os profissionais de saúde, parceiro, familiares e outras gestantes.

\section{Objeto Virtual de Aprendizagem sobre pré-natal para adolescentes grávidas no contexto da atenção básica}

O OVA sobre pré-natal para adolescentes grávidas no contexto da atenção básica foi denominado GESTAQ e na tela inicial, há breve apresentação e nome da pesquisadora. $\mathrm{O}$ usuário inicia a navegação ao clicar sobre o ícone "Entrar", disponível no canto superior direito da página do Curso. Em seguida é direcionado ao cadastro de usuário e senha. Ao inserir os dados, o usuário é direcionado ao GESTAQ composto por cinco semanas, conforme figura 1 .

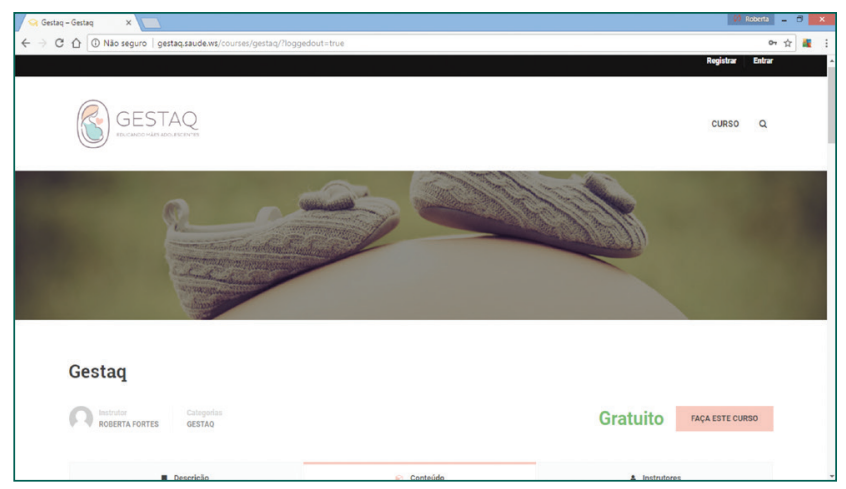

Figura 1. Tela inicial do GESTAQ

A semana 1 foi intitulada "Comece por aqui" e correspondeu à ambientação do GESTAQ. Nesta semana, foram fornecidas informaçóes sobre: objetivos, conteúdos, duração de cada unidade de ensino (semana) e forma de acesso. Foi também incluído o vídeo que contava a história da adolescente que acabava de descobrir a gravidez e ao término era feito um convite aos usuários para que interagissem no fórum de apresentação. Para acessar ao fórum, era preciso apenas clicar na ferramenta "fórum de discussão", disponível logo abaixo do vídeo.

A partir da semana 2, nas telas iniciais de cada unidade de ensino o usuário assistia um vídeo sobre breve descrição das atividades que seriam realizadas e participava do fórum de discussão.

\section{Avaliação do objeto virtual de aprendizagem sobre pré-natal para adolescentes grávidas no contexto da atenção básica}

Dos juízes em Enfermagem em Saúde da Mulher, verificou-se maioria do sexo feminino ( $4-80 \%)$, com projeto de pesquisa na área pré-natal (4 $80 \%)$ e todos $(5-100 \%)$ com orientação de trabalhos acadêmicos, artigos publicados e participação em bancas avaliadoras da área. A média do tempo de formação foi de 23,6 (DP $\pm 9,3)$, sendo a maioria mestre $(3-60 \%)$ e com especialização em Saúde da 
Mulher $(4-80 \%)$. A média do tempo de docência na área do pré-natal foi de 13,4 anos $(\mathrm{DP} \pm 3,2)$ e de atuação na área 15,6 anos $(\mathrm{DP} \pm 10,3)$. A pontuação média nos critérios de seleção dos juízes foi de 22 pontos $(\mathrm{DP} \pm 10,1)$, sendo a mínima 10,3 e a máxima, 38 pontos.

Dos juízes em Informática evidenciou-se que todos $(5-100 \%)$ eram do sexo masculino e tinham experiência profissional em desenvolvimento de website, e que a maioria $(4-80 \%)$ tinha especialização na área de desenvolvimento de web e experiência profissional em desenvolvimento de Ambiente Virtual de Aprendizagem. Nos critérios os juízes atingiram pontuação média de 3,8 pontos $(\mathrm{DP} \pm 1,8)$, sendo a mínima três e máxima sete pontos.

Os dados obtidos na validação da qualidade por juízes em Enfermagem em Saúde da Mulher estão apresentados na tabela 1 .

Tabela 1. Avaliação do Objeto Virtual de Aprendizagem sobre pré-natal por juízes em Enfermagem em Saúde da Mulher $(n=05)$

\begin{tabular}{|c|c|c|c|}
\hline Itens avaliados & $\begin{array}{c}\text { Pontuação na } \\
\text { escala Likert }\end{array}$ & $\begin{array}{l}\text { Total } 5(100) \\
\mathrm{n}(\%)\end{array}$ & \%* \\
\hline \multirow[t]{6}{*}{ Qualidade do conteúdo } & 1 & - & \multirow[t]{6}{*}{100} \\
\hline & 2 & - & \\
\hline & 3 & - & \\
\hline & 4 & $2(40)$ & \\
\hline & 5 & $3(60)$ & \\
\hline & NA & - & \\
\hline \multirow{6}{*}{$\begin{array}{l}\text { Alinhamento dos objetivos de } \\
\text { aprendizagem }\end{array}$} & 1 & - & \multirow[t]{6}{*}{80} \\
\hline & 2 & - & \\
\hline & 3 & $1(20)$ & \\
\hline & 4 & $1(20)$ & \\
\hline & 5 & $3(60)$ & \\
\hline & NA & - & \\
\hline \multirow[t]{6}{*}{ Feedback e adaptação } & 1 & - & \multirow[t]{6}{*}{80} \\
\hline & 2 & - & \\
\hline & 3 & $1(20)$ & \\
\hline & 4 & $2(40)$ & \\
\hline & 5 & $2(40)$ & \\
\hline & NA & - & \\
\hline \multirow[t]{6}{*}{ Motivação } & 1 & - & \multirow[t]{6}{*}{80} \\
\hline & 2 & - & \\
\hline & 3 & $1(20)$ & \\
\hline & 4 & $2(40)$ & \\
\hline & 5 & $2(40)$ & \\
\hline & NA & - & \\
\hline
\end{tabular}

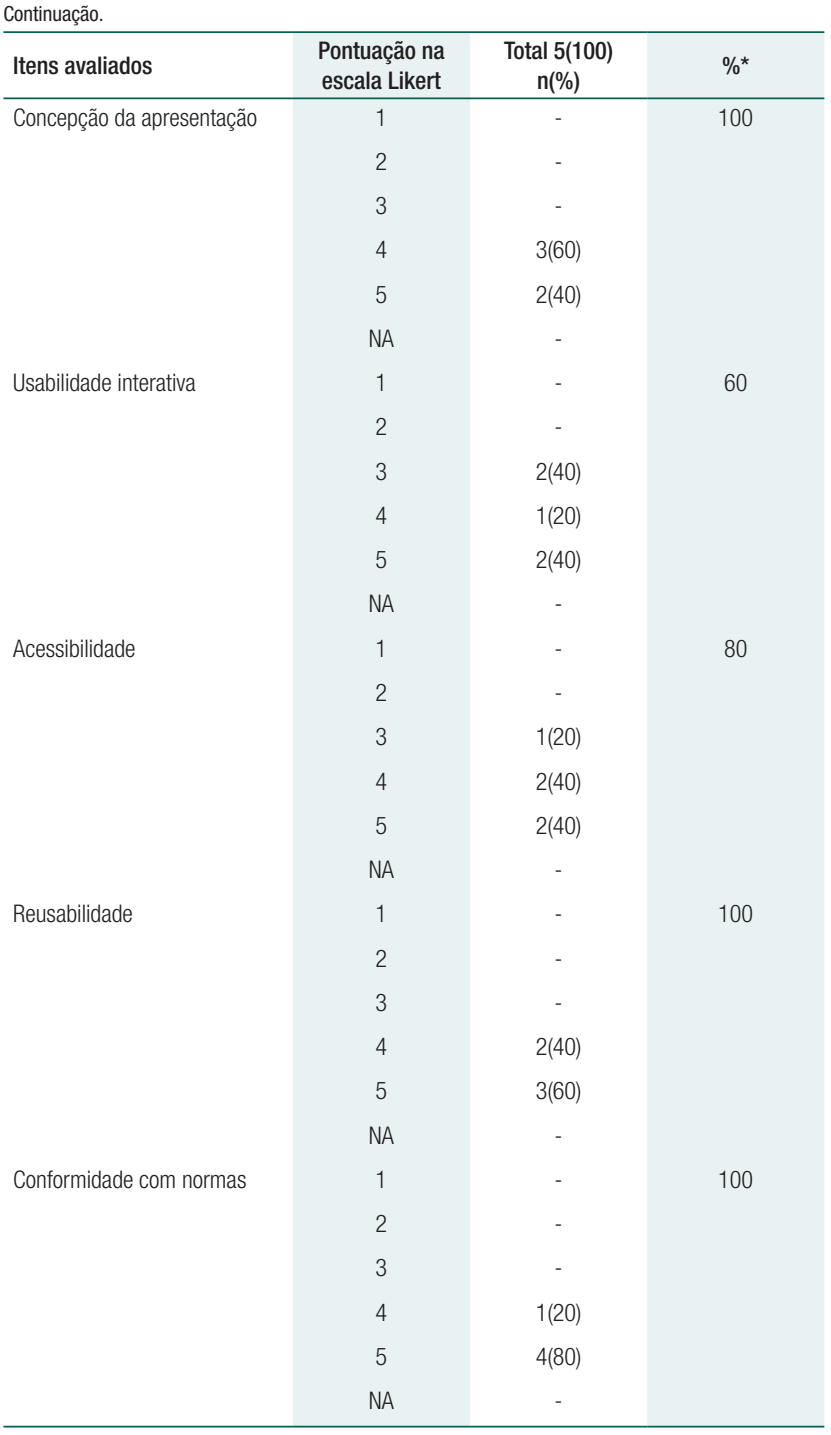

*4 - boa qualidade e 5 - excelente qualidade

Observou-se na tabela 1 que, com exceção da usabilidade interativa, todos os outros itens obtiveram percentual igual ou superior a $80 \%$, nos escores 4 e 5 , de acordo com as respostas dos juízes em Saúde da Mulher. No que se referiu à usabilidade interativa, verificou-se que $60 \%$ das respostas foram para os escores 4 e 5 . Os dados obtidos na avaliação da ergonomia por juízes em Informática estão apresentados na tabela 2 .

Verificou-se pela tabela 2 que as subvariáveis da funcionalidade, usabilidade e eficiência obtiveram percentual igual ou superior a $80 \%$ das respostas, com escores 3 ou 4, por juízes em Informática. Destacou-se como sugestáo apontada pelos juízes em Informática: a melhoria do layout da intervenção educativa, por meio da substituição dos termos 
Tabela 2. Avaliação do Objeto Virtual de Aprendizagem sobre pré-natal por juízes em Informática $(\mathrm{n}=05)$

\begin{tabular}{|c|c|c|c|c|}
\hline Variável & Subvariável & $\begin{array}{l}\text { Pontuação na escala } \\
\text { Likert }\end{array}$ & $\begin{array}{c}\text { Total } 5(100) \\
\mathrm{n}(\%)\end{array}$ & $\%$ * \\
\hline \multirow[t]{20}{*}{ Funcionalidade } & \multirow{4}{*}{$\begin{array}{l}\text { O AVA utiliza os recursos } \\
\text { de forma eficiente. }\end{array}$} & 1 - Inadequado & - & \multirow[t]{4}{*}{100} \\
\hline & & 2 - Pouco adequado & - & \\
\hline & & 3 -Adequado & $1(20)$ & \\
\hline & & 4 - Muito adequado & $4(80)$ & \\
\hline & \multirow{4}{*}{$\begin{array}{l}\text { As funções de apoio } \\
\text { estão implementadas. }\end{array}$} & 1 - Inadequado & - & \multirow[t]{4}{*}{100} \\
\hline & & 2 - Pouco adequado & - & \\
\hline & & 3 - Adequado & $1(20)$ & \\
\hline & & 4 - Muito adequado & $4(80)$ & \\
\hline & \multirow{4}{*}{$\begin{array}{l}\text { Apresenta mecanismos } \\
\text { de interação e } \\
\text { comunicação. }\end{array}$} & 1 - Inadequado & - & \multirow[t]{4}{*}{100} \\
\hline & & 2 - Pouco adequado & - & \\
\hline & & 3 -Adequado & $3(60)$ & \\
\hline & & 4 - Muito adequado & $2(40)$ & \\
\hline & \multirow{4}{*}{$\begin{array}{l}\text { Os conteúdos podem } \\
\text { ser acessados de forma } \\
\text { não-linear. }\end{array}$} & 1 - Inadequado & - & \multirow[t]{4}{*}{100} \\
\hline & & 2 - Pouco adequado & - & \\
\hline & & 3 -Adequado & $2(40)$ & \\
\hline & & 4 - Muito adequado & $3(60)$ & \\
\hline & \multirow{4}{*}{$\begin{array}{l}\text { Possui ferramentas } \\
\text { síncronas e assíncronas. }\end{array}$} & 1 - Inadequado & - & \multirow[t]{4}{*}{100} \\
\hline & & 2 - Pouco adequado & - & \\
\hline & & 3 -Adequado & $4(80)$ & \\
\hline & & 4 - Muito adequado & $1(20)$ & \\
\hline \multirow[t]{28}{*}{ Usabilidade } & \multirow{4}{*}{$\begin{array}{l}\text { O AVA é fácil de ser } \\
\text { utilizado. }\end{array}$} & 1 - Inadequado & - & \multirow[t]{4}{*}{100} \\
\hline & & 2 - Pouco adequado & - & \\
\hline & & 3 -Adequado & - & \\
\hline & & 4 - Muito adequado & $5(100)$ & \\
\hline & \multirow{4}{*}{$\begin{array}{l}\text { As informações de ajuda } \\
\text { são claras e fáceis de } \\
\text { serem entendidas. }\end{array}$} & 1 - Inadequado & - & \multirow[t]{4}{*}{100} \\
\hline & & 2 - Pouco adequado & - & \\
\hline & & 3 -Adequado & $3(60)$ & \\
\hline & & 4 - Muito adequado & $2(40)$ & \\
\hline & \multirow{4}{*}{$\begin{array}{l}\text { A quantidade de } \\
\text { informação inserida em } \\
\text { cada tela é adequada. }\end{array}$} & 1 - Inadequado & - & \multirow[t]{4}{*}{100} \\
\hline & & 2 - Pouco adequado & - & \\
\hline & & 3 -Adequado & $1(20)$ & \\
\hline & & 4 - Muito adequado & 04 & \\
\hline & \multirow{4}{*}{$\begin{array}{l}0 \text { tamanho e o tipo de } \\
\text { fonte do conteúdo estão } \\
\text { adequados. }\end{array}$} & 1 - Inadequado & - & \multirow[t]{4}{*}{100} \\
\hline & & 2 - Pouco adequado & - & \\
\hline & & 3 -Adequado & - & \\
\hline & & 4 - Muito adequado & $5(100)$ & \\
\hline & \multirow{4}{*}{$\begin{array}{l}\text { A escolha das cores no } \\
\text { ambiente e os contrastes } \\
\text { entre elas são adequados }\end{array}$} & 1 - Inadequado & - & \multirow[t]{4}{*}{80} \\
\hline & & 2 - Pouco adequado & $1(20)$ & \\
\hline & & 3 - Adequado & $1(20)$ & \\
\hline & & 4 - Muito adequado & $3(60)$ & \\
\hline & Os recursos audiovisuais & 1 - Inadequado & - & 80 \\
\hline & & 2 - Pouco adequado & $1(20)$ & \\
\hline & & 3 -Adequado & $1(20)$ & \\
\hline & & 4 - Muito adequado & $3(60)$ & \\
\hline & A linguagem está & 1 - Inadequado & - & 100 \\
\hline & interatıva. & 2 - Pouco adequado & - & \\
\hline & & 3 - Adequado & $1(20)$ & \\
\hline & & 4 - Muito adequado & $4(80)$ & \\
\hline
\end{tabular}

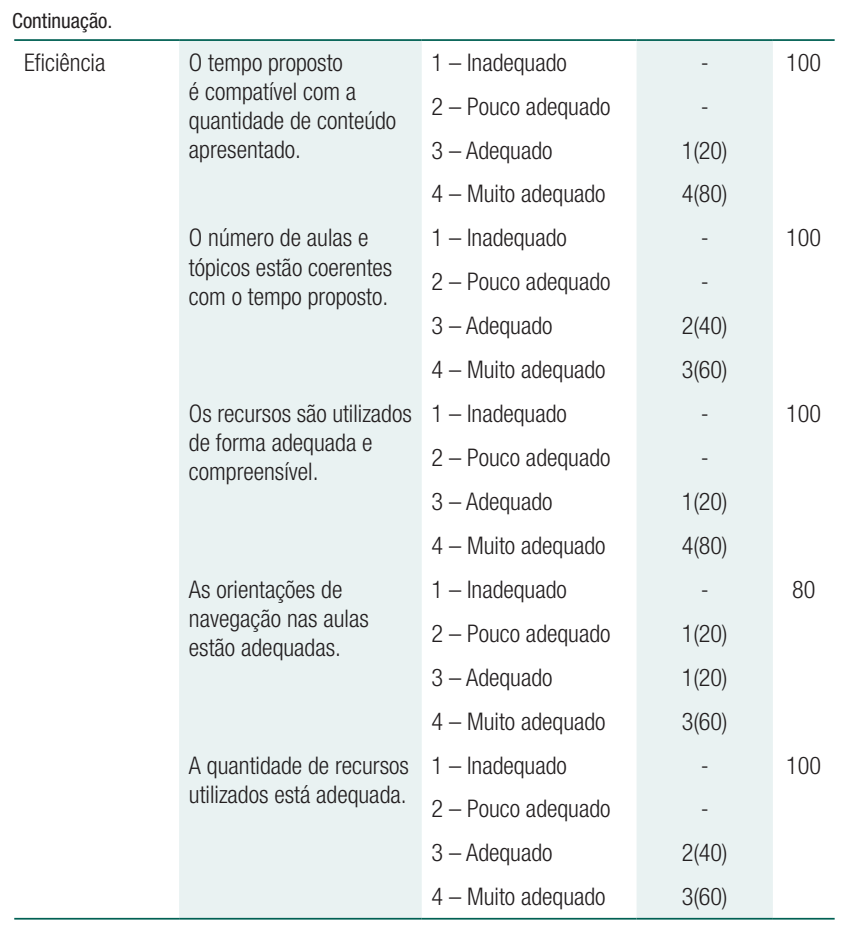

*4 - boa qualidade e 5 - excelente qualidade

em inglês por português e da criação de diferenciação de cores entre os tópicos e subtópico. Estas recomendaçóes foram atendidas.

\section{Discussão}

Ressalta-se como limitação do estudo que o processo de avaliação do OVA sobre pré-natal aconteceu apenas com juízes de conteúdo e técnicos, sendo importante sua avaliação clínica com as adolescentes grávidas que utilizarão o OVA.

Outro aspecto é o fato do conteúdo do OVA não contemplar: direitos reprodutivos, contracepção pós-parto, violência contra mulher, saúde mental e infecçóes sexualmente, apesar da sua construção ter sido baseada no Manual de Atenção ao Pré-Natal do Ministério da Saúde, ${ }^{(20)}$ levantamento de necessidades de aprendizagem das adolescentes grávidas sobre pré-natal e avaliação de juízes em Enfermagem em Saúde da Mulher que não sugeriram a inclusão dessas temáticas.

Acredita-se que o uso do OVA sobre pré-natal auxiliará a prática do enfermeiro e de outros profissionais de saúde que desenvolvem atividades educativas sobre esse tema, sendo recurso digital inova- 
dor, acessível e importante para promoção de saúde e prevenção de agravos materno-infantis em adolescentes grávidas no contexto da atenção básica.

\section{Objeto virtual de aprendizagem sobre pré-natal para adolescentes grávidas no contexto da atenção básica}

A caracterização do público-alvo (adolescentes grávidas) mostrou elevado índice de telefone celular entre as adolescentes grávidas e acesso à internet de casa, estando em acordo com o que revelou a Pesquisa Nacional por Amostra de Domicílio (PNAD) realizada pelo IBGE. ${ }^{(6)}$ Segundo a mesma pesquisa, $78,3 \%$ da populaçáo tem telefone celular e $80 \%$ da população brasileira com idade entre 15 e 19 anos é usuária da internet.

A internet foi o principal meio de informação utilizado pelas adolescentes para esclarecer dúvidas sobre a gravidez, sendo detectadas várias necessidades de aprendizagem, pois a maioria nunca tinha participado de atividade educativa durante o prénatal. O Ministério da Saúde determina a necessidade e importância de, durante o pré-natal, os profissionais de saúde realizarem atividades educativas com gestantes, de modo a sanar dúvidas, medos e anseios, porém na prática, verifica-se carência de tais ações. ${ }^{(20)}$

Além disto, a busca de informaçôes na internet deve ser realizada com cautela porque nem sempre contém informaçóes confiáveis. Pesquisa realizada pelo Instituto Francês de Prevenção e Educação em Saúde com jovens de 15 a 30 anos revelou que a maior parte dos participantes, em especial os adolescentes, usava e confiava em informaçóes da internet, e entre os temas mais frequentes procurados estavam os relacionados à maternidade. ${ }^{(14)} \mathrm{O}$ estudo alerta que este meio, embora seja importante fonte de informação, requer a orientaçáo prévia por profissionais de saúde, bem como acesso a conteúdo confiável.

As dúvidas mais frequentes das adolescentes grávidas foram definidas como conteúdo do OVA sobre pré-natal. Estes dados obtidos com as adolescentes grávidas proporcionaram o planejamento do OVA e foi de suma importância, visto que a temática gestação é vasta, e quando ocorre na adolescên- cia se amplia ainda mais, pois há vários subtemas importantes.

O Ministério da Saúde preconiza que durante o pré-natal sejam trabalhados vários aspectos através de atividades educativas. ${ }^{(20)}$ Devido a isto, percebeu-se que para construção do OVA, seria relevante delimitar mais especificamente as características e necessidades sentidas por adolescentes grávidas para que fosse possível contribuir em pontos que mais geravam dúvidas, inseguranças, medos, e que refletiam diretamente na qualidade de vida das mesmas.

Os objetivos educacionais, baseados na Taxonomia de Bloom foram organizados, conforme o preconizado pela literatura, do mais simples para o mais complexo, de forma que o objetivo anterior fosse pré-requisito para o seguinte. ${ }^{(21)}$

Posteriormente, traçou-se o design, sendo, nesta fase, fundamental a criação de ambientes que proporcionem aprendizagem eficiente, em que se faz necessário o uso das mais diferentes estratégias disponíveis, considerando a realidade vivenciada pelos educandos. ${ }^{(18)}$ Por isso, os conteúdos selecionados foram desenvolvidos com a utilização de referência do Ministério da Saúde, que dispóe de manual técnico voltado para atenção à gestante. ${ }^{(20)}$ As aulas foram elaboradas e, junto com o profissional web designer, foram planejados e desenvolvido o storyboard, sendo utilizado: texto, imagens, som, animação e fóruns para interação.

O desenvolvimento do OVA foi realizado no WordPress, a escolha desse software como AVA considerou alguns aspectos: ter facilidade de acesso independente do dispositivo tecnológico utilizado, possibilitar o uso de ferramentas integradas e que tenham flexibilidade para acesso, e proporcionar interação educador-educando e interatividade. Esses aspectos foram considerados baseados na análise inicial das demandas das gestantes adolescentes, e são fundamentais a ser considerados, pois, para que o processo de construçáo de conhecimento em um AVA ocorra com qualidade e atinja os objetivos educacionais, é preciso considerar ambiente, conteúdo, interatividade e pessoas. ${ }^{(27)}$

$\mathrm{Na}$ implementação do OVA, utilizou-se diferentes ferramentas disponíveis no AVA, bem como delimitou-se o uso do aplicativo WhatsApp, com 
a finalidade de aumentar a interação e estimular o acesso ao OVA sobre pré-natal.

Os recursos disponibilizados pelo WhatsApp (texto, vídeo, áudio, imagem, demonstração de emoção através figuras e animaçóes) são responsáveis pelo seu poder atrativo e uso intenso, sobretudo entre adolescentes, por isso estudos evidenciam sua capacidade em potencializar o processo educativo. ${ }^{(28-30)}$ Assim, foi criado pela pesquisadora um grupo nesse aplicativo, em que foram incluídas todas as gestantes adolescentes que participaram do OVA sobre pré-natal, visando evitar desistências ou não adesão.

\section{Avaliação do Objeto Virtual de Aprendizagem sobre pré-natal para adolescentes grávidas no contexto da atenção básica}

Os juízes em Enfermagem em Saúde da Mulher e Informática mostraram-se experientes e capacitados para avaliar o OVA, pois na pontuação adotada para seleção, os juízes atingiram média superior à exigida.

Estudos que elaboraram ambientes de aprendizagem ratificaram a importância do processo de avaliação, ao realizarem a avaliação de qualidade e ergonômica após construção de intervenção educativa online, como se verifica na pesquisa que desenvolveu hipermídia educativa sobre infecções sexualmente transmissíveis (IST) para acadêmicos de Enfermagem, ${ }^{(31)}$ como no trabalho que avaliou OVA sobre estomias intestinais de eliminação. ${ }^{(32)}$

Ao realizar a avaliação de OVA sobre a Sistematização da Assistência de Enfermagem (SAE) foram avaliados aspectos relacionados ao material didático disponível por profissionais juízes (especialistas) na área, para proporcionar abordagem pedagógica adequada e com qualidade. ${ }^{(33)}$ Logo, a avaliação é necessária para garantir que o educando tenha acesso a conteúdo contextualizado e condizente com suas experiências prévias. ${ }^{(25)}$

$\mathrm{Na}$ avaliação da qualidade do OVA sobre pré-natal por juízes em Enfermagem em Saúde da Mulher, o único item que teve avaliação inferior a $70 \%$ foi usabilidade interativa, que atingiu 60\% das respostas positivas, os outros $40 \%$ dos juízes o avaliaram como bom. Portanto, este achado não invalida esse item, pois, no geral, foi bem avaliado, além disso, há estudo que considera como alvo respostas que pontuem cada um dos itens como pelo menos bom. ${ }^{(34)}$ Tal avaliação da usabilidade interativa ocorre por se tratar dos primeiros testes com a tecnologia informacional e educacional. ${ }^{(35)}$

Resultados semelhantes para avaliação da qualidade foram encontrados em um estudo que usou os mesmos itens para validação de aplicativo móvel que avalia o nível de consciência em pacientes graves, e em outro que também usou os itens para validar um OVA que mensura a dor aguda. ${ }^{(33,35)}$ Diante dos resultados obtidos com os juízes de Saúde da Mulher, pode-se afirmar que o conteúdo do OVA apresenta qualidade para o processo de ensino-aprendizagem de adolescentes grávidas.

$\mathrm{Na}$ avaliação ergonômica do OVA sobre pré-natal realizada por cinco juízes em Informática, foram avaliadas as variáveis funcionalidade, usabilidade e eficiência, que apresentam subvariáveis. $\mathrm{Na}$ funcionalidade, as cinco subvariáveis que a compóem foram avaliadas acima do valor esperado de $70 \%$, visto que as resposta positivas alcançaram 100\% de concordância pelos juízes. Tal achado indica que o OVA utilizou de maneira eficiente os recursos disponíveis, de modo a satisfazer as necessidades educativas das gestantes adolescentes.

As sete subvariáveis que compóem a usabilidade também foram bem avaliadas pelos juízes, apenas a relacionada ao uso das cores e aos recursos audiovisuais da intervenção educativa obtiveram nível de concordância de $80 \%$, nas demais subvariáveis o nível de concordância foi de $100 \%$. O desenvolvimento de contrastes de cores entre os tópicos e subtópicos foi uma sugestáo atendida, porém se manteve o uso de cores claras.

Esta alteração, de uso das cores claras no layout do programa é importante para evitar distraçóes nos educandos. ${ }^{(31,32)}$ Frente à avaliação da usabilidade e do ajuste realizado, assegura-se que a tecnologia informacional e educacional possui a capacidade de ser compreendida, apreendida, operada e atraente para as adolescentes grávidas.

Das cinco subvariáveis que compóem a eficiência, quatro obtiveram nível de concordância de $100 \%$ entre os juízes, apenas a que avaliava as orientações de navegação o nível de concordância foi de $80 \%$, que revela o poder da tecnologia infor- 
macional e educacional em apresentar desempenho apropriado frente aos recursos utilizados.

Diante da avaliação de conteúdo e técnica do OVA, acredita-se que possa contribuir para o processo de ensino-aprendizagem de adolescentes grávidas, de modo a proporcionar conhecimentos que podem repercutir em aspectos relacionados à qualidade de vida.

\section{Conclusão}

O desenvolvimento do OVA sobre pré-natal para as adolescentes grávidas denominado GESTAQ exigiu processo sistematizado e flexível, fundamentado na identificação das necessidades de aprendizagem do público-alvo. O GESTAQ foi bem avaliado quanto aos aspectos de qualidade e ergonômicos. Acreditase que a utilização do GESTAQ possa representar recurso digital complementar ao processo educativo, sobretudo, na atenção primária, pelos enfermeiros e demais profissionais da saúde, podendo ser ofertado e ter seu uso incentivado para fornecer suporte as orientaçóes que são dadas na consulta de pré-natal.

\section{Agradecimentos}

À Universidade Federal do Piauí (oportunidade de realizar o doutorado) e aos juízes que participaram da validação e avaliação da cartilha educativa.

\section{Colaborações}

Santiago RF contribuiu com a concepção do projeto, execução da pesquisa, redação do artigo, revisão crítica relevante do conteúdo intelectual e aprovação final da versão a ser publicada. Nery IS e Andrade EMLR contribuíram com a concepção do projeto, redação do artigo, revisão crítica relevante do conteúdo intelectual e aprovação final da versão a ser publicada. Mendes IAC e Viana MCA contribuíram com a revisão crítica relevante do conteúdo intelectual e aprovação final da versão a ser publicada.

\section{Referencias}

1. Lee $M$, Lee H, Kim Y, Kim J, Cho M, Jang J, Jang H. Mobile appbased health promotion programs: a systematic review of the literature. Int J Environ Res Public Health. 2018; 13;15(12). doi.org/10.3390/ ijerph15122838.

2. Marcolino MS, Oliveira JA, Ribeiro AL. Text messaging for prevention and treatment of cardiovascular disease: time to move on. Heart. 2017;103(12):893-4.

3. Dorje T, Zhao G, Scheer A, Tsokey L, Wang J, Chen Y, Tso K, Tan BK, Ge J, Maiorana A. SMARTphone and social media-based Cardiac Rehabilitation and Secondary Prevention (SMART-CR/SP) for patients with coronary heart disease in China: a randomised controlled trial protocol. BMJ Open. 2018;8(6):e021908.

4. Wiley DA, editor. The instructional use of learning objects. Logan (UT): Utah State University; 2002. Connecting learning objects to instructional design theory: a definition, a metaphor, and a taxonomy; p. 6.

5. Fabre MC, Tamusiunas F, Tarouco LM. Reusabilidade de objetos educacionais. Rev Novas Tecnol Educ. 2003;1(1):1-11.

6. Pacheco KC, Azambuja MS, Bonamigo AW. The construction of learning objects on communicable diseases for community health agents. Rev Gaucha Enferm. 2018;38(4):e20170073.

7. Salvador PT, Mariz CM, Vítor AF, Ferreira Júnior MA, Fernandes MI, Martins JC, et al. Validação de Objeto Virtual de Aprendizagem para apoio ao ensino da sistematização da assistência de enfermagem. Rev Bras Enferm. 2018;71(1):11-9.

8. Warmling CM, Pires FS, Baldisserotto J, Levesque M. Ensino da bioética: avaliação de um Objeto Virtual de Aprendizagem. Rev Bioetica. 2016;24(3):503-14.

9. Lara MV, Borges S, Welter M, Mello-Carpes PB. Objetos de aprendizagem como coadjuvantes do processo de ensino-aprendizagem de Fisiologia humana. Rev Ensino Bioquím. 2014;12(1):34-47.

10. Gadioli B, Fulquini FL, Kusumota L, Gimenes FR, Carvalho EC. Construção e validação de um Objeto Virtual deAprendizagem para o ensino da semiologia vascular venosa periférica. Esc Anna Nery. 2018;22(4):e20180043.

11. Salvador PT, Bezerril MS, Mariz CM, Fernandes MI, Martins JC, Santos VE. Objeto e ambiente virtual de aprendizagem: análise de conceito. Rev Bras Enferm. 2017;70(3):572-9.

12. Queiroz MV, Menezes GM, Silva TJ, Brasil EG, Silva RM. Grupo de gestantes adolescentes: contribuições para o cuidado no pré-natal. Rev Gaúcha Enferm. 2016; 37(Esp):e2016-0029.

13. Aba YA, Kömürcü N. Antenatal education on pregnant adolescents in Turkey: prenatal adaptation, postpartum adaptation, and newborn perceptions [Korean Soc Nurs Sci]. Asian Nurs Res (Korean Soc Nurs Sci). 2017;11(1):42-9.

14. Beck F, Richard JB, Nguyen-Thanh V, Montagni I, Parizot I, Renahy E. Use of the internet as a health information resource among French young adults: results from a nationally representative survey. J Med Internet Res. 2014;16(5):e128.

15. Blázquez Barba M, Gómez Romero D, Frontaura Fernández I, Camacho Ojeda A, Rodríguez Salas FM, Toriz Cano H. [Use of new technologies by adolescents in the search for health information]. Aten Primaria. 2018;50(9):547-52.

16. Akhavan P, Arefi MF. Quality development of learning objects: comparison, adaptation and analysis of learning object evaluation frameworks for online courses. J Inform Technol Applic Educ. 2014;3(2):57-66. 
17. Polit DF, Beck CT. Fundamentos de pesquisa em Enfermagem: avaliação de evidências para a prática da enfermagem. 7a ed. Porto Alegre: ArtMed; 2011.

18. Filatro. A. Design instrucional contextualizado: educação e tecnologia. 2a ed. São Paulo: Senac; 2007. p.70.

19. Instituto Brasileiro de Geografia e Estatística (IBGE). Pesquisa Nacional por Amostras de Domicílios - Acesso à internet e a televisão e posse de telefone móvel celular para uso pessoal 2013 [Internet]. [citado 2018 Set 3]. Disponível e : http://biblioteca.ibge.gov.br/visualizacao/livros/liv93373.pdf

20. Brasil. Ministério da Saúde. Secretaria de Atenção à Saúde. Departamento de Atenção Básica. Atenção ao pré-natal de baixo risco. Brasília: Ministério da Saúde; 2012.

21. Ferraz AP, Belhot RV. Taxonomia de Bloom: revisão teórica e apresentação das adequações do instrumento para definição de objetivos instrucionais. Gest Prod. 2010;17(2):421-31.

22. Freitas LV, Teles LM, Lima TM, Vieira NF, Barbosa RC, Pinheiro AK, et al. Exame físico no pré-natal: construção e validação de hipermídia educativa para a enfermagem. Acta Paul Enferm. 2012; 25(4):581-8.

23. Pasquali L. Instrumentação psicológica: fundamentos e práticas. Porto Alegre: ArtMed; 2010.

24. Nesbit J, Belfer K, Leacock T. Learning Object Instrument Review (LORI). User Manual. E-Learning Research and Assessment Network (eLera) Portal for Online Objects in Learning (POOL) [Internet]. 2009 [cited 2018 Jun 10]. Available from: http://www.academia.edu/7927907/ Learning_Object_Review_Instrument_LORI_

25. Trindade CS, Dahmer A, Reppold CT. Objetos de aprendizagem: uma revisão integrativa na área da saúde. J Health Inform. 2014;6(1):209.

26. Sperandio DJ. A tecnologia computacional móvel na sistematização da assistência de enfermagem: avaliação de um software protótipo [tese]. Ribeirão Preto (SP): Universidade de São Paulo; 2008.
27. Miranda GS. Tecnologia, interação e interatividade: desafios para 0 docente em ambientes virtuais de aprendizagem [dissertação]. Pouso Alegre (MG): Universidade do Vale do Sapucaí; 2015.

28. Araújo PC, Bottentuit Júnior JB. 0 aplicativo de comunicação WhatsApp como estratégia no ensino de filosofia. Temática. 2015;11(2):11-23.

29. Kirchner K, Razmerita L. Collaborative Learning in the Cloud - A CrossCultural Perspective of Collaboration. Proceedings of the 26th ACM Conference on Hypertext \& Social Media. Guzelyurt, Northern Cyprus - September 01 - 04, 2015. p.333-6. [cited 2018 Sep 2]. Available from: https://dl.acm.org/citation.cfm?id=2700171.2804452

30. Leite NC, Silva MO. WhatsApp: caracterização do gênero chat em contexto de ensino de línguas estrangeiras. Texto Llivre. 2015; 8(1): 85-97.

31. Holanda VR, Pinheiro AK. Technology for education of sexually transmitted diseases: hypermedia validation. Rev Enferm UFPE Online. 2016; 10(6) 2082-90.

32. Braga CS, Andrade EM, Luz MH, Monteiro AK, Campos MO, Silva FM, et al. Construção e validação de um Objeto Virtual de Aprendizagem sobre estomias intestinais de eliminação. Invest Educ Enferm. 2016;34(1):120-7.

33. Salvador PT, Mariz CM, Vítor AF, Ferreira Júnior MA, Fernandes MI, Martins JC, et al. Validação de objeto virtual de aprendizagem para apoio ao ensino da sistematização da assistência de enfermagem. Rev Bras Enferm. 2018; 71(1):16-24.

34. Alvarez AG. Tecnologia persuasiva na aprendizagem da avaliação da dor aguda em enfermagem [tese]. Florianópolis (SC): Universidade Federal de Santa Catarina; 2014.

35. Barros WC. Aplicativo móvel para aprendizagem da avaliação do nível de consciência em adultos (OMAC) [tese]. Florianópolis (SC): Universidade Federal de Santa Catarina; 2015. 